\title{
1 : 25000 map of the urban geology of Hannover, German A new series of maps within the framework of a new project
}

\section{Project objectives}

The Geological Survey of Lower Saxony (Niedersächsiches Landesamt für Bodenforschung, NLfB) commenced a project in 1995 to compile information on the urban geology of Hannover, which is the capital city of Lower Saxony. This project was undertaken in co-operation with the Hannover City Surveyor's Office (Landeshauptstadt Hannover, Stadtvermessungsamt), the Federal Institute of Geosciences and Natural Resources (Bundesanstalt für Geowissenschaften und Rohstoffe, BGR), and the Joint Geoscientific Research of the German State Geological Surveys (Geowissenschaftliche Gemeinschaftsaufgaben, GGA), also in Hannover. The results were published as a series of maps in 1998.

Rohde, Peter \& Becker-Platen, Jens Dieter (eds.) (1998): Geologische Stadtkarte

Hannover 1 : 25 000, A. Festgestein, B. Grundwasser, C. Geotechnik, mit Erläuterungen [1 : 25000 Map of the Urban Geology of Hannover, A. Solid Geology, B. Groundwater, C. Geotechnics, with Explanatory Notes]. 156 pp., 37 figs., 5 tables, 3 maps; Hannover (Niedersächsisches Landesamt für Bodenforschung [Geological Survey of Lower Saxony]). ISBN 3-9801097-9-8.

The land use, and therefore the "utilisation" of the subsurface rocks as a scarce natural resource, is particularly intensive in the urbanised region of the city of Hannover, which has a population of over 0.5 million people within an area of about $200 \mathrm{sq}$. km. Consequently, the compilation of comprehensive geoscientific databases and the geoscientific expertise for the decision-makers in both politics and administration, also for the practising engineers and technicians in the private sector and government, was a principal objective of the project. Although the city already had an engineering geology map at 1: 10,000 scale and a hydrogeological map at 1: 20,000 scale from the 1950's and 1970 's, as well as its own drill-hole archive and measurement data from the groundwater observation service, the comprehensive archive material in Hannover City Surveyor's Office and the Geological Survey was not available in a format suitable for the contemporary requirements for large-scale reviews, and therefore did not comprise a sufficiently modern database for planning purposes. As a result, there were two aims for the project:

1. The comprehensive databases in the city administration and the Geological Survey as well as a wide range of other geoscientific knowledge should be made available quickly for the purposes of construction planning and groundwater utilisation.

2. Supplementary investigations, which could be undertaken in the short-term, should also be included.

In view of the expense and amount of work required for this project, it was considered that it would be unsatisfactory if the final product could only be used by a few technically oriented specialists. It is even more important that the individual user of non-renewable natural resources should acquire a perception for their scarcity and value. Therefore, a broader spectrum of the general public should also be made aware of the interesting and varied aspects of the natural resource "geological formations". Among other things, this includes the historical development of geological understanding as well as the limits of the accuracy of statements based on geological investigations and reports which, such as in this case, are based on boreholes and geophysical methods and from which regional interpretations are derived. This new cartographic presentation, together with the richly illustrated Explanatory Notes, is the attempt to provide politicians, administrators and citizens with facts about the geology of their city. This information can then be applied by these people in their decision-making and provides them with an understanding of the environmental consequences of their decisions. In this way, the project should also be considered as a local contribution to the practical realisation of Agenda 21 from Rio de Janeiro 1992.

\section{What were the requirements of the project, and how was it realised?}

The city of Hannover is located in the area between the hills of southern Lower Saxony that are formed by Mesozoic bedrock and the Quaternary unconsolidated deposits that characterise the North German Plain. In at least $90 \%$ of the map area, however, the bedrock is concealed beneath unconsolidated cover that is a minimum of $0.5 \mathrm{~m}$ thick. The average thickness of the cover of unconsolidated deposits is $10 \mathrm{~m}$; thicknesses of unconsolidated sediments up to $20 \mathrm{~m}$ are prevalent and the sediment filling locally attains $70 \mathrm{~m}$ in the ancient channels. Therefore the nature of the bedrock and the depth to the top of the bedrock, as well as the succession of the unconsolidated sedimentary cover, can only be studied by drilling. The post-1945 reconstruction activities in the city, which was severely damaged during the Second World War, and the construction of an underground railway since 1968 , have both contributed substantially to information on the geological formations. The collaboration between the City Surveyor's Office and the Geological Survey on engineering geological and hydrogeological matters has always been very important and productive.

An area of $480 \mathrm{sq}$. km. was included in the investigations and studies for this map project, of which an area of about 360 sq. $\mathrm{km}$. is presented on the new maps. About 10,000 stratigraphic borehole profiles were available at the Geological Survey and a similar number at the City Surveyor's Office. Some of these boreholes were registered at both authorities as a result of earlier exchanges of data, but even they sometimes have different nomenclatures. It goes without saying that there are considerable differences in both the drilling depths and reliability of the borehole descriptions. About 3000 boreholes were selected from both databases according to the criteria of depth and quality of the information, and the borehole descriptions were interpreted geologically. The reliable determination of the bedrock surface was an important objective in the selection procedure. The borehole descriptions were harmonised according to the data processing standards and were recorded in a digital file (STADTHAN96).

It was not possible to drill any new or additional boreholes because of both cost and time factors. The gaps in the data could therefore only be interpolated, with certain reservations, by the application of geological expertise. This was particularly the case for a densely built-up area of complex Quaternary geology near the airport, where airborne magnetometry could have been applied as an alternative source of information, but was not permitted due to the safety aspects. In addition the compilation of the information from an area marked by the presence of a salt dome and its gypsum caprock, as well as the Tertiary and Quaternary unconsolidated deposits within and overlying the dome, 
proved to be very difficult due to the extreme irregularities related to subrosion-as a result, blank patches on the map could not be avoided in this area. As to the thickness distribution of the unconsolidated cover material in the whole map area it would have been unsatisfactory to derive it directly from the borehole file of insufficient coverage. Therefore, at first the model of the underlying polygenetic bedrock relief has been developed on the base of genetic background information. Only afterwards the model for the thickness of the unconsolidated cover material was derived from the digitised contour lines of the bedrock relief and from the digital topographic relief model at 1: 5000 (file of the Lower Saxony state-owned enterprise "Landesvermessung und Geobasisinformation Niedersachsen"), and is a contribution of the Joint Geoscientific Research of the German State Geological Surveys (GGA) in Hannover.

Reports and publications dating from 1928 and 1954-1975 could be used in part for the stratigraphic classification of the bedrock surface. In addition comprehensive new micropalaeontological determinations, also including some revisions, of 950 samples were required. This work was undertaken in the micropalaeontological laboratory of the Geological Survey. The samples were from Cretaceous rocks, in particular from the Albian and the transitions to the Aptian and Cenomanian, and were related to a revision of the Albian-Cenomanian subdivision.

The work on the hydrogeological topics proceeded in a different manner. There are 2700 groundwater observation sites within the city area. The Geological Survey and the City Surveyor's Office carried out water level measurements at 1500 of these sites during the winter months from December 1995 to April 1996. These yielded unusual low values. In addition, ground water samples were collected from 200 sites and were analysed at the Laboratory for Water and Soil Geochemistry at the Federal Institute for Geosciences and Natural Resources (BGR), Hannover. The analyses referred to 3 characteristic physical parameters, 37 inorganic substances and 14 organic compounds. Four types of ground water, based on the proportions of calcium, hydrogen carbonate and sulphate as well as the acidity and degree of mineralization, can be identified in the map area. An evaluation of the ground water corrosiveness on concrete showed that there are three degrees of corrosion according to the DIN 4030 standard.

The topographic map of the city of Hannover was available as the for the publication of the results of the project in map form. In its original form, this map is at a scale of 1: 20,000 and includes the street names. An appropriate area of this map, with a selection of street names, was reduced to a scale of 1: 25,000 , which is the standard scale for the fundamental geological maps in Germany. In this way it should be simple for the new maps to be compared directly with the existing 6 map sheets of the city area in the definitive "Geologische Karte von Niedersachsen [Geological Map of Lower Saxony] 1: 25,000".

The cartographic work was undertaken conventionally in order to avoid any risks during the technological changeover to digital cartography in the Geological Survey, which has now been completed. Digital methods were used, however, for some of the cartographic tasks, such as the construction of the map for the thickness of unconsolidated deposits, as is described above.

\section{The new maps}

The maps presented to the public in September 1998 consists of 6 parts. These are:

- Three coloured maps presenting seven geological and geotechnical topics, at a scale of 1: 25,000 , cut to a size of $108 \mathrm{~cm}$ $\times 72 \mathrm{~cm}$, folded to $12 \mathrm{~cm} \times 24 \mathrm{~cm}$.

- A borehole map at a scale of 1: 100,000.

- A booklet of Explanatory Notes about the seven topics on the maps as well as 37 easily comprehensible and explanatory illustrations in the figures section at the beginning of the book, as well as

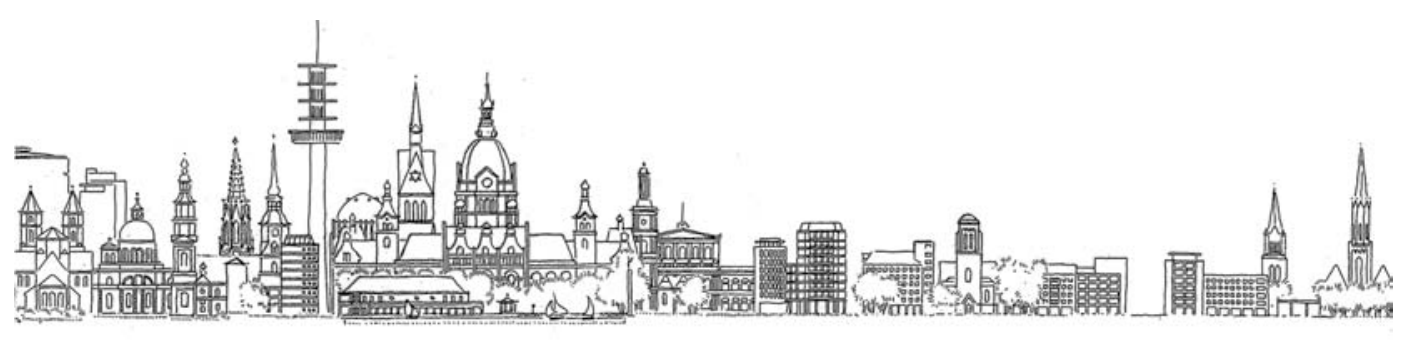

\section{Geologische Stadtkarte Hannover} $1: 25000$

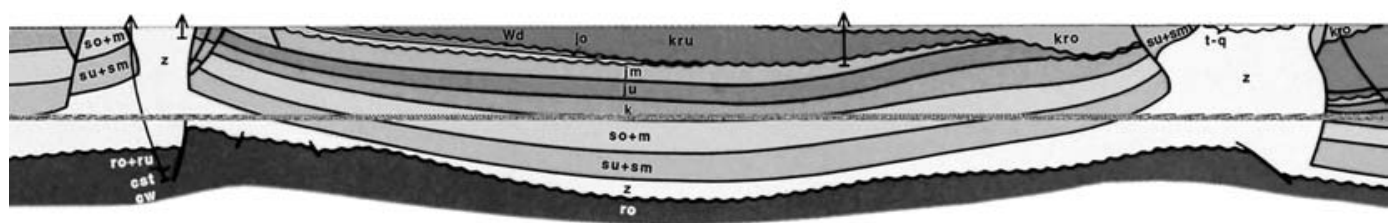

Figure 1 The new 1: 25,000 Map of the Urban Geology of Hannover, co-ordinated by P. Rohde and J.D. Becker-Platen, includes one map on each of the topics: Solid Geology, Groundwater and Geotechnics as well as a booklet of Explanatory Notes, in which the illustrations demonstrate the geologically interesting features of the urban geology. The figure on the cover shows a geological cross-section through the approximately $4 \mathrm{~km}$ thick sequence of beds from the Upper Cretaceous (kro) to the pre-halite Permian (Rotliegendes, ro, ru) as well as the Upper Carboniferous (cst; cw). The two salt domes illustrate the effects of the Upper Permian (Zechstein, z) halite on the structure throughout the whole of the Mesozoic. (The cross-section is from the Geotektonischer Atlas von NW-Deutschland, F. Kockel et al., Hannover 1996). 


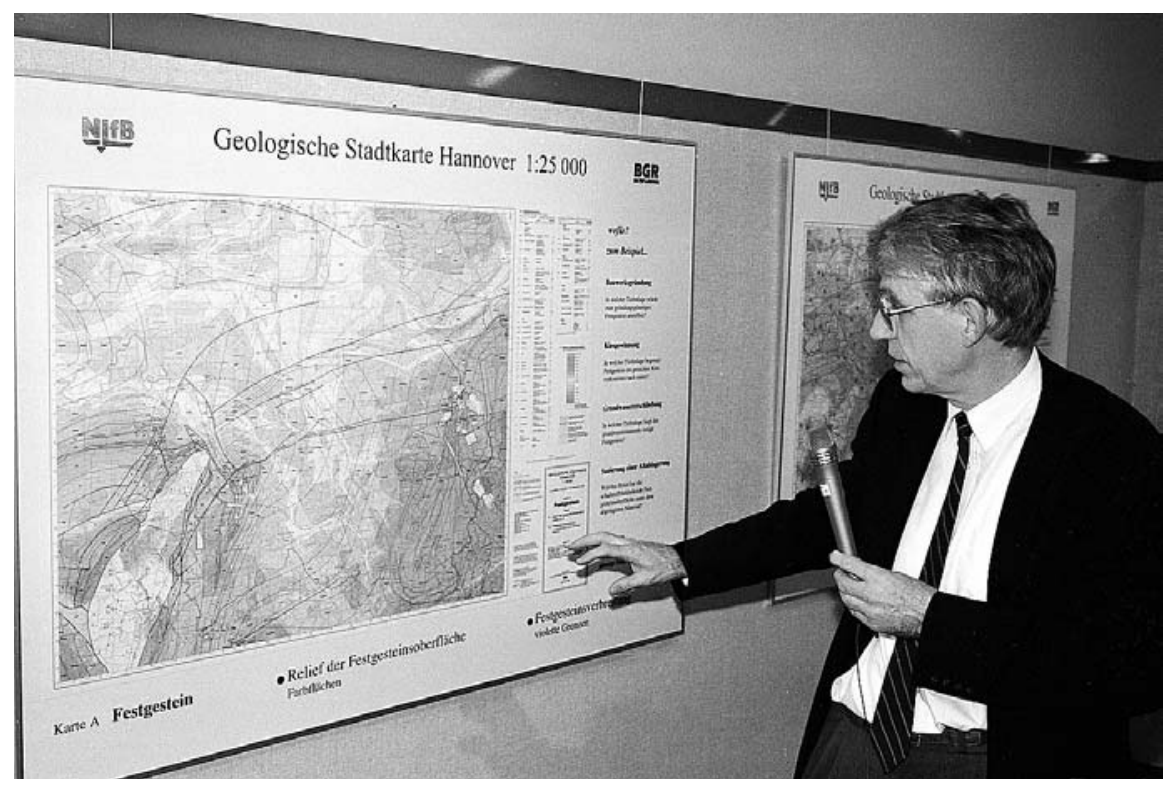

Figure 2 The President of the Federal Institute of Geosciences and Natural Resources (BGR) as well as the Geological Survey of Lower Saxony (NLfB) in Hannover, Professor Dr.-Ing. F.-W. Wellmer, commenting on the new map "Solid Geology" at an exhibition.

- A booklet with the values for 40 characteristic inorganic chemical and physical parameters from 200 ground water sampling sites.

The following were not published:

- The digital borehole file STADTHAN96 (Geological Survey of Lower Saxony and City Surveyor's Office), and

- The digital file of ground water investigations, as well as the organic chemistry analyses (Federal Institute for Geosciences and Natural Resources, BGR, Laboratory for Water and Soil Geochemistry).

The $\mathbf{7}$ topics shown on the $\mathbf{3}$ maps are:

\section{Map A Solid Geology}

Topic Al Relief of the bedrock surface (in $\mathrm{m}$ above mean sea level)

Topic A2 Bedrock geology (Tertiary and Quaternary deposits are not shown)

Map B Groundwater

Topic B1 Hydrogeology (distribution of groundwater aquifers)

Topic B2 Hydrochemistry (distribution of groundwater types)

Topic B3 Depth to groundwater-table (contours in $\mathrm{m}$ above mean sea level)

Map C Geotechnics

Topic C1 Thickness of unconsolidated deposits

Topic C2 Degree of the groundwater corrosion for concrete (according to DIN 4030).

The topics on maps A1, B1 and C1 are presented in full colour, and all the other topics are superimposed on this base. It was decided to present topic A2 by lines marking the geological contacts together with the notation of the stratigraphic units. Topic B3 is presented by contours of the depth to the groundwater-table as well as lines showing the location of a groundwater divide and arrows indicating the direction of the groundwater flow. The domains in Topics B2 and $\mathrm{C} 2$ are identified by notation, and the borders of the domains are marked by coloured stripes. Coloured circles, and for Topic C2 coloured sectors, illustrate the chemical characteristics of the groundwater at each of the sample sites.

In order to inform the potential endusers about the publication of the maps, the Geological Survey and the City Surveyor's Office organised an exhibition in the Municipal Office of Planning and Building Inspection as well as reports in the press, radio and the television for passengers at the underground railway stations in the city. The maps were also presented at the 50th Meeting of the German Quaternary Association (Deutsche Quartärvereinigung, DEUQUA), in Hannover and also at the Geo-Berlin '98 meeting on the occasion of the 150th anniversary of the German Geological Society (Deutsche Geologische Gesellschaft) in Berlin. Furthermore, technical specialists were informed in the newsletter of the Chamber of German Engineers. The three-part map-set, together with the Explanatory Notes booklet and the analytical documentation booklet, can be purchased at GeoCenter, Internationales Landkartenhaus, Postfach 80 0830; D-70508 Stuttgart; Fax: *49/711/781946-54, as well as in bookshops for EURO 14.57 (DM 28.50).

Even before their official publication, the maps were provided for several major construction projects: for example, the construction of a railway line of the planned cityline (S-Bahn) network; the extension of a part of the "Mittelland" Canal with regard to conforming to the requirements for "Europa ships"; as well as the redevelopment of a previously contaminated area belonging to the city. Unfortunately the map showing the relief of the bedrock surface (Topic A1) was not taken into consideration during the excavations for the foundations of a major building project, with the unhappy result of water inflows in the foundation excavation as well as further damage during the attempts to rectify the problem.

Some of the consequences of the work on this map project are informative. For example, regional information was obtained on the distribution of toxic hydrocarbons in the groundwater, as well as on the effects of oversalting related to the spreading of salt on the roads during winter. It is sometimes not possible to provide a satisfactory solution to some geotechnical problems even after special investigations, especially if the latter are far too closely focused on the target of these investigations. For example, the city authorities in Hannover require information about the regional consequences of the influence on the groundwater of the city's central waste disposal site, which is located above a prominent, partly sand-filled, fluvioglacial channel in the clay-rich bedrock.

The maps are not yet complete. Additional maps on the following topics are in preparation:

- Near-surface unconsolidated deposits and bedrock (to a depth of $2 \mathrm{~m}$ ), as well as

- Soils (urban soils and near-natural soils)

Furthermore the potential tourist interest, which has not yet been appreciated, will be reflected in, for example, information about geologically interesting sites to visit. Finally a compilation of a digital model of the complete Quaternary succession of the unconsolidated deposits would be beneficial.

\section{Peter Rohde}

Department of Geological Research and Planning,

Geological Survey of Lower Saxony (Niedersächsisches Landesamt für

Bodenforschung),

P.O. Box 510153 ,

D-30631 Hannover,

GERMANY 